\begin{tabular}{|c|l|}
\hline Title & What is Coworking? : A Theoretical Study on the Concept of Coworking \\
\hline Author(s) & Uda, Tadashi \\
\hline Citation & Discussion Paper, Series A , 265, 1-15 \\
\hline Issue Date & 2013 12 \\
\hline Doc URL & http://hdl.handle.net/2115/53982 \\
\hline Type & bulletin (article) \\
\hline File Information & DPA 265.pdf \\
\hline
\end{tabular}

Instructions for use 
Discussion Paper,Series A,No.2013-265

What is Coworking?

A Theoretical Study on the Concept of Coworking

Tadashi UDA

12.2013

Graduate School of Economics \& Business Administration

Hokkaido University

Kita 9 Nishi 7, Kita-Ku, Sapporo 060-0809, JAPAN 


\title{
What is Coworking?
}

\section{A Theoretical Study on the Concept of Coworking}

\author{
Tadashi UDA
}

Graduate School of Economics and Business Administration, Hokkaido University

\begin{abstract}
The purpose of this paper is to examine the concept of coworking on the basis of reviewing discussions related to this concept and to demonstrate issues for theoretical development. Specifically, first an overview is made on the practical unfolding of coworking, which is the subject of increasing attention in Japan and overseas in recent years. Next, questions that have so far largely been untouched such as what kind of concept coworking is and how it differs from existing related issues, are examined utilizing the two concepts of coworker, i.e. working individual, and coworking space, i.e. workplace. On that foundation, three points are presented as issues for theoretical development. First, to systematically consider coworking based on the knowledge of previous research on working individuals and workplaces. Second, to construct an elaborate theoretical framework based on the review of related previous research. And lastly, to grasp the actual conditions and mechanisms of coworking by focusing on actors that strive to invoke the concepts of coworking while redefining the way of working and associated practices.
\end{abstract}

Keywords: coworking, coworker, coworking space, way of working 


\section{Introduction}

The purpose of this paper is to examine the concept of coworking on the basis of reviewing discussions related to this concept and to demonstrate issues for theoretical development. In more specific terms, upon considering what coworking is and how it differs from existing related issues, the theoretical perspectives on this concept are investigated.

The paper from the next section comprises the following structure. In Section 2, unfolding of the phenomenon of coworking is overviewed; in Section 3, the concept of coworking and its theoretical status are examined; and finally in Section 4, the preceding arguments are sorted and the significance of this paper and future issues are presented.

\section{Unfolding of Coworking}

More and more attention is being directed towards coworking in recent years. Coworking means "a way of working in which working individuals gather in a place to create value while sharing information and wisdom by means of communication and cooperating under the conditions of their choices"1. Here, there are two notable points. First is the attributes of individuals are not restricted to a specific job, occupation, and organization. Second is the workplace is physically shared by them. Accordingly, in specific terms, this concept points to a way of working where freelancers, small-scale entrepreneurs or organization members, etc. who possess separate jobs share a work place and flexibly cooperate under the circumstances while mutually communicating.

Arguments that emphasize the novelty of coworking, which aspires to balance individual autonomy with collaboration with others, are occasionally found; however, such a way of working has been practiced over the ages. An example was the gathering of artists at the atelier La Ruche ${ }^{2}$, which was established in the Montparnasse district of Paris at the beginning of the $20^{\text {th }}$ Century $^{3}$. Numerous famous artists of the École de Paris such as Chagall, Modigliani and Soutine produced avant-garde works while spending their days and nights together in this communal atelier that was designed like a beehive ${ }^{4}$. It is interesting that such a diversity of artists of differing origins, principles and styles were physically linked in the space of a

\footnotetext{
1 The background to this definition is described in detail in Section 3. Moreover, coworking is not simply a way of 2 This polygonal building was provided for unheralded artists by the French sculptor Alfred Boucher in 1902 (Okada, 2004). La Ruche literally means the beehive, and Boucher designed the atelier with the artists viewed as bees. Even in 2003, roughly 100 years since its founding, La Ruche was being used by more than 70 artists.

3 See Jones, Sundsted and Bacigalupo (2009).

${ }^{4}$ See Okada (2004).
} 
common atelier while seeking to explore new forms of artistic expression ${ }^{5}$.

Other examples include the artists who gathered in the cluster of ateliers referred to as "Ikebukuro Montparnasse" in Tokyo from the 1920s to the $1940 \mathrm{~s}^{6}$, the artists who congregated at the "Factory" that was set up by Andy Warhol in New York in $1964^{7}$, and the writers who worked at the "Writers Room" that was established in New York in $1978^{8}$. So it can be seen that this style of working has practiced in both Eastern and Western countries.

Nevertheless, concerning why the term coworking and the way of working it entails have come to receive so much attention in recent years, this way of working that had conventionally been limited to specific professional types such as artists have come to be embodied by freelancers and small-scale entrepreneurs and thus have come to be widely recognized as a viable option for individuals engaged in intellectual labor.

One of the first people to show an example of this was Brad Neuberg, who worked as a freelance engineer in San Francisco. As an independent worker, Brad tended to feel loneliness and struggle for ideas, so he opened a space called the "Hat Factory" in a building that was formerly (literally) a hat factory and started working there with some friends in $2006^{9}$. After that, similar examples gradually spread mainly in major American cities and eventually to Europe ${ }^{10}$.

At the same time, coworking spaces were successively established in various countries. Starting with "Citizen Space ${ }^{11}$ ", which is the oldest currently existing coworking space that was established by Tara Hunt, one of the original members of "Hat Factory," and others, there are now said to be more than 2,000 such spaces all over the world ${ }^{12}$. In Japan, too, Tomio Ito founded "Cahootz" - the first coworking space - in Kobe in 2010, and since then more than 200 such spaces have been established in a little over two years ${ }^{13}$.

Even if looking at the movement within Japan, there has been a succession of new initiatives such as introduction of the "Coworking VISA jp" ${ }^{14}$, which is a system for promoting mutual use between facilities, creation of support organizations such as the Sapporo Coworking Supporters $(\mathrm{SCS})^{15}$, and establishment of Coworking Coop ${ }^{16}$.

\footnotetext{
5 See Shibata (1999).

${ }^{6}$ See Hijikata, Shinmyo and Ejiri (2004).

7 See Ratcliff (1983).

8 See Jones et al. (2009).

9 Kaihatsu Kouhou (The PR Brochure of Hokkaido Development Association), No. 593, p. 2.

${ }^{10}$ See Satani (2012).

${ }^{11}$ See Jones et al. (2009)

12 Kaihatsu Kouhou (The PR Brochure of Hokkaido Development Association), No. 593, p. 2.

13 Ibid.

14 Japanese version of Coworking VISA. People who register as monthly members at certain facilities can use other participating spaces free of charge or at a discount rate from one to a few days. As of September 2012, 40 spaces had subscribed to this system (Ibid.)

15 This was the first coworking support organization to be based on collaboration between industry, government and academia in Japan. It was founded in March 2012 in a joint effort between four agencies, namely North Pacific Bank, Ltd., Hokkaido Bureau of Economy, Trade and Industry, City of Sapporo and Center for Regional Economic and Business Networks in Hokkaido University. Japan Finance Corporation subsequently became a participant, so it is now composed of five agencies (Ibid. , p. 1). It specifically has conducted support activities such as constructing a
} 
It can thus be seen that coworking is steadily spreading not only in Europe and America, but Japan as well and supporting systems are also being established. In line with such developments, there are increasing references to the history and current conditions of and prospects for coworking in all forms of media. In spite of that, there is hardly any research that directly or systematically discusses the contents or status of coworking, let alone the actual state and causes and effects of this concept ${ }^{17}$. The next section sorts and examines existing arguments and prepares the theoretical basis of coworking.

\section{Theoretical Examination of Coworking}

The preceding section mainly confirmed the following two points. First, coworking redefines

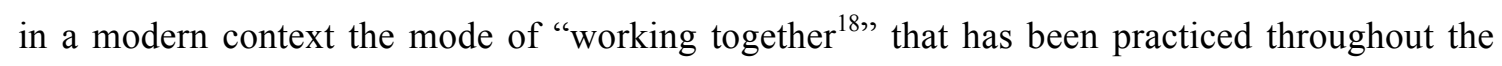
ages, and practical examples of this have come to be vigorously practiced primarily in the United States and also Europe and Japan since the mid-2000s. Second, in spite of the confirmation of such a trend, theoretical examination of this phenomenon has hardly been carried out at all.

Accordingly, in this section it aims to first sort through existing definitions of coworking and then present subordinate concepts. Next, Comparing these subordinate concepts with associated concepts and considering their theoretical statuses are carried out. Such an approach is followed because, through recognizing the coworking dimension, for which theoretical examination is still sparse, on the basis of existing arguments, and discussing similarities and differences with other associated concepts on the same table, it is possible to relativize the concept of coworking in a more concrete and systematic manner.

To this end, first definitions of coworking in various literature and media are confirmed.

coworking information hub, conducting taking order for coworking spaces, and planning and running coworking-related events (Kaihatsu Kouhou (The PR Brochure of Hokkaido Development Association), No. 588, pp. 15-16).

${ }^{16}$ This association was established with the objective of conducting programs that contribute to coworkers. It was established in August 2012 by Tomio Ito, the representative of Cahootz, and others. Its main activities comprise promotion of joint contracting, provision of education and training, construction of information sharing systems, enhancement of welfare, and support for the opening and running of coworking spaces throughout the country. For details, see the website at http://coworking.coop/.

${ }_{17}$ Currently, the only research that directly or systematically discusses coworking is that by Spinuzzi (2012). In this, based on qualitative survey of nine coworking spaces in Austin, Texas in the United States, an attempt is made to clarify three research questions, i.e. what is coworking, who coworks, and why cowork? As a result, a number of highly suggestive facts were presented, for example, there is a large disparity between space managers and space users regarding the definition of coworking; there is a mismatch between actual users and operators in terms of targets; users have expectations regarding location, work environment, and mutual partnership and contact, and so on. Furthermore, from the viewpoint of activity theory that seeks to gauge human activities in terms of their social and cultural context, examination concerning the configurations of coworking is added. However, this work from start to finish is basically an analysis of activities of coworking, but it hardly examines how the extracted knowledge is positioned and what it means in theoretical unfolding on working individuals and workplaces.

${ }_{18}$ In a wider sense, it means to work together. 
Table 1 summarizes definitions given by entities both in Japan and overseas countries that have pioneered coworking activities, irrespective of differing standpoints such as practitioner, supporter or investigator. On comparing each definition, leaving aside some differences in expression and point of emphasis, all of them make reference to "individuals who work" together with other people of differing attributes, and "places" that are shared by the working people. In other words, coworking can be more specifically and systematically grasped from the two dimensions of "working individual" called coworker and "workplace" referred to as the coworking space.

The following paragraphs compare and examine in order how these subordinate concepts differ from other associated concepts.

Concepts associated with working individual, i.e. coworker, include freelance, small-scale entrepreneur and organization member ${ }^{19}$. As can be ascertained in Table 1, coworkers are, conceptually, individuals who work together with various others of differing attributes in a certain place, and this definition can be applied to freelancers, small-scale entrepreneurs and organization members. However, at the present time, most coworkers comprise freelancers or small-scale entrepreneurs who work in the creative or IT fields ${ }^{20}$.

So, first of all, what are the differences between individual coworkers and freelancers? Freelancers, through setting up independently, can acquire greater work autonomy than people in organizations. On the other hand, because they set up their office at home or in a rented tenant space, they have less physical contact and communication with others in workplace than not only organization members and small-scale entrepreneurs but also coworkers, for whom communication with other users is encouraged ${ }^{21}$. However, although there is less contact with others in workplace, the level of diversity or difference of attributes with other people they do come into contact with is, basically, higher than among members who work in the same organization and small-scale entrepreneurs. Even so, freelancers are not at the level of coworkers who have the potential to come into contact with others who are strangers on a daily basis.

Next, small-scale entrepreneurs tend to be viewed as being similar to freelancers. However, they jointly execute a business, albeit small, with other people. Therefore, the degree of contact with others in the workplace is almost equal to that among organization members, and of course higher than that among freelancers and also than coworkers who can autonomously control the amount of contact they have with others. Having said that, due to the scale of business, the

\footnotetext{
19 Another example is teleworkers, although teleworkers include types who correspond to organization members working at home, and types that correspond to freelancers and small-scale entrepreneurs. Since it is difficult to conduct conceptual discusiion without reviewing related previous researches, reference is omitted in this paper.

${ }^{20}$ For example, see Kaihatsu Kouhou (The PR Brochure of Hokkaido Development Association), No 588.

21 As was mentioned in the preceding section, Brad Neuberg, who was working freelance, opened the "Hat Factory" in an effort to break out of feeling loneliness and struggling for ideas.
} 
diversity of other people that come into contact in the workplace is slightly higher than among organization members who may come into contact with others in the same organization, but of course it is lower than among coworkers and also freelancers who have individual autonomy.

Table 1. Definition of Coworking

\begin{tabular}{|c|c|}
\hline Source & Definition \\
\hline Coworking Wiki ${ }^{22}$ & $\begin{array}{l}\text { Independent professionals and those with workplace flexibility } \\
\text { work better together than they do alone }\end{array}$ \\
\hline $\begin{array}{l}\text { Tomio Ito }^{23} \text { (representative of } \\
\text { Cahootz) }\end{array}$ & $\begin{array}{l}\text { Concept and associated facilities where workers who hold } \\
\text { respective jobs share information and wisdom through not } \\
\text { only sharing the same place (space) but also communicating }\end{array}$ \\
\hline DeGuzman and Tang $(2011)^{24}$ & $\begin{array}{l}\text { Set-up and dynamics of a diverse group of people who don't } \\
\text { necessarily work for the same company or on the same } \\
\text { project, working alongside each other, sharing the working } \\
\text { space and resources }\end{array}$ \\
\hline $\begin{array}{l}\text { Hokkaido Bureau of } \\
\text { Economy, Trade and } \\
\text { Industry }^{25}\end{array}$ & $\begin{array}{l}\text { Generic terms for a new way of working in which people who } \\
\text { don't belong to enterprises or organizations (or going beyond } \\
\text { the bounds of enterprises and organizations) and possess } \\
\text { various capabilities and values congregate to share know-how } \\
\text { and ideas, stimulate each other and collaborate while actively } \\
\text { communicating }\end{array}$ \\
\hline Satani $(2012)^{26}$ & $\begin{array}{l}\text { A work style in which people of differing occupations and } \\
\text { jobs gather and share the same workplace and enhance each } \\
\text { other through actively communicating and sharing wisdom } \\
\text { and information }\end{array}$ \\
\hline Spinuzzi $(2012)^{27}$ & $\begin{array}{l}\text { A superclass that encompasses the good-neighbors and } \\
\text { good-partners configurations as well as other possible } \\
\text { configurations that similarly attempt to network activities } \\
\text { within a given space }\end{array}$ \\
\hline
\end{tabular}

22 "Coworking Wiki" is a website resources provided for people who are concerned with or interested in coworking. For its definition, see http://wiki.coworking.com/w/page/16583831/FrontPage. Incidentally, the aforementioned coworking space "Citizen Space" also adopts this definition.

${ }^{23}$ See the Cahootz website (http://cahootz.jp/).

${ }^{24}$ See p. 22.

${ }^{25}$ See Kaihatsu Kouhou (The PR Brochure of Hokkaido Development Association), No. 588, p. 13.

${ }^{26}$ See p. 16.

27 See p. 433. 
Next, organization members at first sight may appear to have lower association than coworkers, and only points of difference may be focused on. However, from the viewpoint of working in a physically shared workplace with others, they have greater similarity than freelancers. In addition, compared to coworkers who, despite sharing the same workplace, do not necessarily have to communicate or cooperate with other users, organization members have a higher degree of contact with other people. Even so, as was mentioned previously, since the people that organization members physically come into contact with in the office are generally members of the same organization, the level of diversity between contacted people is lower than among not only coworkers but also small-scale entrepreneurs and freelancers.

Based on the comparative examination described above, Figure 1 shows the positioning of each concept.

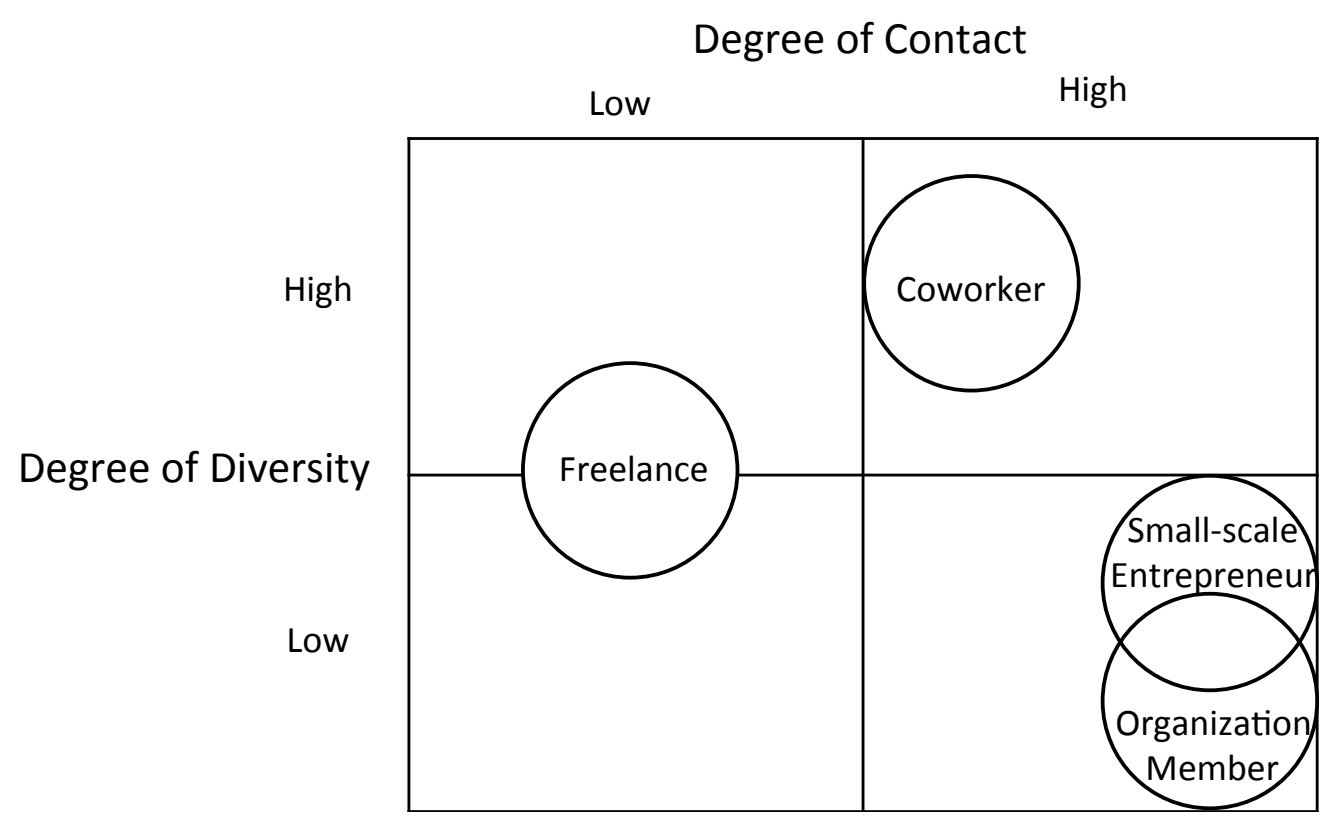

Figure 1. Theoretical status of concepts associated with working individuals

Here, degree of contact refers to the degree of "physical" contact and communication with other people. Meanwhile, degree of diversity refers to the extent of variety of attributes among other people that contact in the "workplace." In terms of the degree of "physical" contact and communication with other people, coworkers have less than organization members and small-scale entrepreneurs, however, in terms of diversity among others that contact in the "workplace," they rank higher than organization members and also small-scale entrepreneurs and freelancers.

The following paragraphs conduct comparative examination of concepts associated with coworking space. This concept is associated with such cases as SOHO (Small Office/Home 
Office), corporate office ${ }^{28}$ and incubation facility. Moreover, SOHOs are classed into SOHOs used as workplaces by freelancers and SOHOs used as workplaces by small-scale entrepreneurs. Meanwhile, corporate offices are used in reference to the work spaces of "organization members" discussed earlier.

Here, before entering into comparative examination of each concept, the place that is coworking space is outlined as follows. Coworking space basically offers membership and drop-in services ${ }^{29}$. Membership refers to the service targeting parties that regularly use a specific coworking space. Users usually pay a monthly usage fee. The size of the fee depends on the location of facilities but it is often set at somewhere between 10,000 20,000 yen in Japan. Moreover, utilized spaces (desk and chair) can either be the fixed type or variable ${ }^{30}$. As for "drop-in," this refers to the service for users that visit facilities without reservation or appointment and pay for services on each visit rather than in monthly units. The usage fee is often set at 1,000 yen per day.

Bearing in mind these points, comparative examination of these concepts is described below.

First, SOHOs for freelancers offer high independence; however, because they offer less proximity to other people than not only corporate offices but also SOHOs for small-scale entrepreneurs and coworking spaces, workers here tend to fall into a solitary state. Of course, compared to corporate offices, because workplaces are more open, workers are free to seek exchanges with the outside world. Even so, compared to coworking spaces that are used day and night by individuals of differing attributes, the degree of openness is generally low.

Turning to SOHOs that are used by small-scale entrepreneurs, these may seemingly appear no different than SOHOs used by freelancers, however, the difference is that the former type is a corporate office that is physically shared by multiple individuals, albeit on a small scale. Accordingly, the type used by small-scale entrepreneurs offers greater proximity to the workplaces of other people than coworking spaces in which selection of facilities and specific spaces is left to the discretion of users, and it is roughly the same as corporate offices in this respect. On the other hand, this type has slightly higher degree of workspace openness than that in corporate offices. This is due to the smaller scale of the workplace, allowing for greater flexibility of organization rules and greater opportunities for cooperation with other workers than that in corporate offices described later. Still, SOHOs that are used by small-scale entrepreneurs have a lower degree of workspace openness than that of freelancer SOHOs, where

\footnotetext{
${ }^{28}$ Offices in medium or larger size enterprises are considered. According to the basic law on small and medium enterprises, medium-scale enterprises in the service sector have six or more employees.

${ }^{29}$ For example, see Satani (2012). In addition, many spaces regularly hold events such as seminars and reading clubs.

${ }^{30}$ Facilities that provide fixed booths can also be seen. For example, coworking space "Dorinoki" in Sapporo has established 28 booths for $1 \sim 4$ people that are divided by $150 \mathrm{~cm}$ high partitions. Usage fees range from 33,000 yen for a single booth measuring $3.2-4.4 \mathrm{~m}^{2}$ to 108,000 for a 4-person booth measuring $14.9 \mathrm{~m}^{2}$. For details, see the Dorinoki site at http://sapporo-odori.jp/dorinoki/.
} 
individuals' ideas can be directly reflected, as well as coworking spaces.

Furthermore, in corporate offices, since constituent members ${ }^{31}$ usually work at adjacently arranged desks, there is a higher degree of proximity to other people's workspaces than that in not only SOHOs for freelancers but also coworking spaces. Having said that, since access tends to be more limited for other people apart from the constituent members and parties concerned than in small-scale offices, corporate offices pale in comparison to not only SOHOs but also coworking spaces in terms of workspace openness.

Finally, the paper also cites incubation facilities, which have more in common with coworking spaces rather than SOHOs and corporate offices. Incubation facilities or business incubators (BI) are facilities ${ }^{32}$ for supporting the businesses of entrepreneurial individuals or corporations $^{33}$. The contents of support are broadly classed into hard factors entailing the provision of work spaces with better cost and location conditions than general tenant or rental offices, and soft factors entailing provision of knowledge and information that contributes to business activities in terms of business strategy, legal affairs and marketing and so forth ${ }^{34}$.

Since work spaces in incubation facilities are usually composed of individual rooms or fixed booths, the degree of proximity to other people's work spaces is of course higher than that in SOHOs for freelancers, although it is lower than in corporate offices, SOHOs for small-scale entrepreneurs, and coworking spaces that are basically open spaces shared by multiple differing entities $^{35}$. Particularly in the case of incubation facilities operated by public agencies, facilities are open to the local community and both charged and free exchange spaces and so on are provided. Therefore, in terms of the degree of openness, these facilities are superior to corporate offices and SOHOs, however, because users tend to occupy spaces for a certain length of time, they are not as open as coworking spaces that provide drop-in service.

Figure 2 shows the position of each concept bearing in mind the comparative examination described above. Here, degree of proximity ${ }^{36}$ signifies the physical degree of proximity to other people's workspaces, while degree of openness refers to the extent that the workplace is open to the outside. Coworking spaces have lower physical proximity to other people's workspaces than corporate offices, but they are more open to the outside than certainly corporate offices and also SOHOs and incubation facilities. Moreover, degree of proximity and degree of openness are

\footnotetext{
${ }^{31}$ Here, white-collar workers are assumed.

32 According to the Ministry of Economy, Trade and Industry, approximately 500 facilities have been established by public agencies (central government, local governments, third sector, chambers of industry and commerce, etc.), and there are other facilities that are established and run by private operators and NPOs. (http://www.meti.go.jp/policy/local_economy/bi/index.html)

33 This includes entities that are currently preparing for establishment.

${ }^{34}$ Concerning details, for example, see the site of the Organization for Small \& Medium Enterprises and Regional Innovation (http://www.smrj.go.jp/venture/index.html).

${ }_{35}$ However, when using fixed booths in coworking space, there is not much difference with incubation facilities.

${ }^{36}$ Moreover, similar results are obtained when the "degree of sharing" of work space is used instead of the degree of proximity.
} 
conceptually in correspondence to the degree of contact and degree of diversity that were previously used for establishing the theoretical position of concepts related to working individuals described earlier. To be more specific, the closer that work places are in terms of physical distance, working individuals have a higher degree of physical contact with other people, and the more that work places are open to the outside, the people that come into contact in the workplace display greater diversity of attributes.

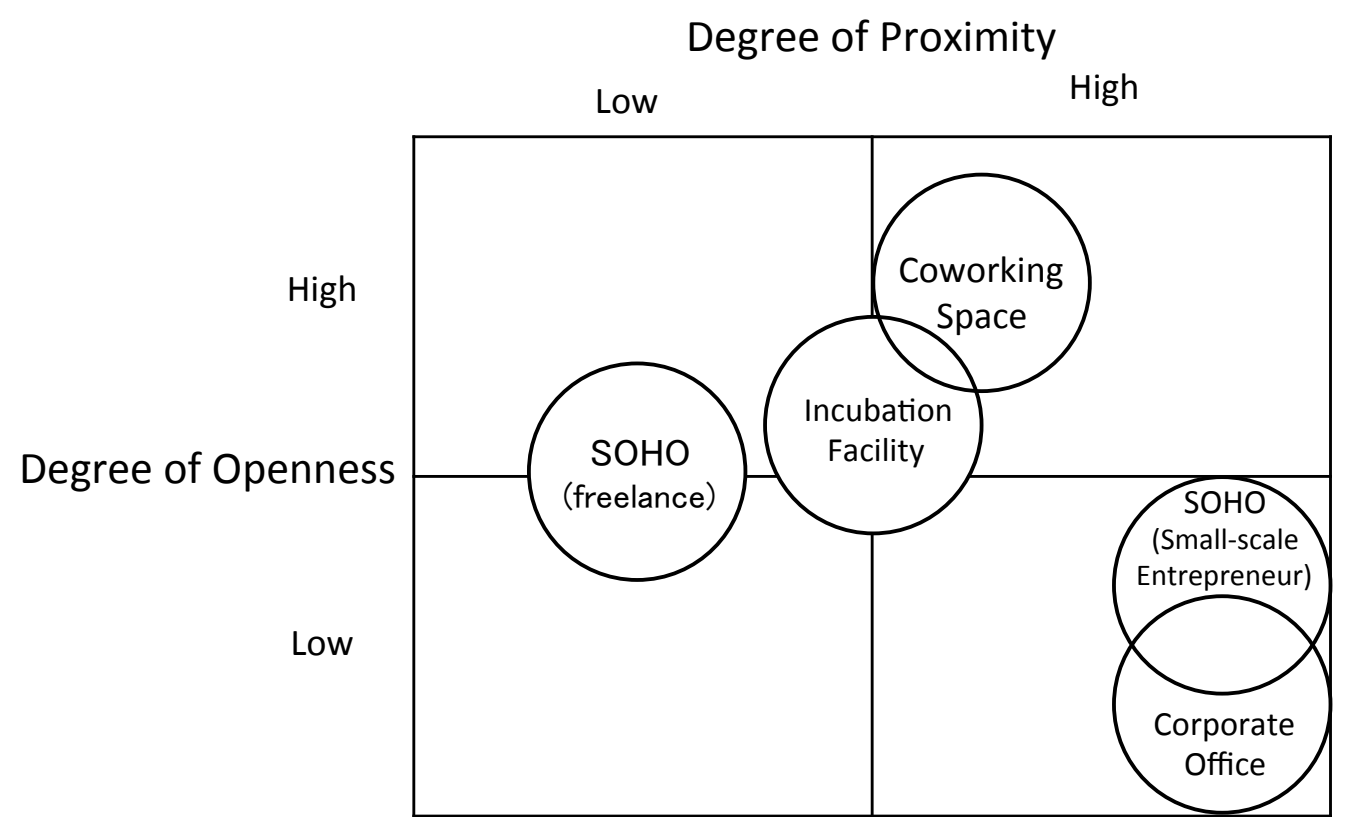

Figure 2. Theoretical status of concepts associated with workplace

The following paragraphs describe some theoretical speculation about coworking while referring to Figure 1 and Figure 2.

The mainstream style of work continues to be that of organization members working in corporate offices. Having said that, the style of establishing an independent business and working in one's own office has come to permeate society as a viable option over the past 20 30 years. As a result, work styles have come to be broadly divided into either working as an organization member or as an independent entrepreneur. Moreover, coworking has become more widespread in recent years. Referring to Figure 1, the period from the 1980s to the 1990s witnessed a shift away from predominantly work as organization members and an expansion of viable alternatives for freelancers and small-scale entrepreneurs ${ }^{37}$, while expansion in the

\footnotetext{
${ }^{37}$ For example, according to Steinmetz and Wright (1989), the number of self-employed workers has suddenly increased in line with the end of the welfare state system and emergence of neo-liberalism Specifically, in the United Kingdom, the number of self-employed increased 1.5 times from 2.2 million to 3.3 million between 1981 1991 (Moralee, 1998), and 1 million out of the extra 1.1 million were self-employed without employees, i.e. freelancers (Fraser and Gold, 2001). See Uda $(2007,2009)$ for a detailed review of existing research on freelancers.
} 
position of coworkers in the top right of the figures has been taking place from the mid-2000s. In terms of Figure 2, in a similar way to the growth of working individuals, there has been expansion from primarily corporate offices to the two types of SOHOs and coworking spaces. Meanwhile, incubation facilities steadily grew in advanced countries from the mid-1980s, and they became more widespread as a socially recognized alternative in the $1990 \mathrm{~s}^{38}$.

In the background to these transformations have been the development of ICT (Information, Communication and Technology), the spread of SNS (Social Networking Service), as well as reappraisal of physical contact (swing-over from excessive dependence on remote communications) and advances in the culture of sharing ${ }^{39}$.

As can be gathered from Figure 1 and Figure 2, coworking, in conceptual terms, is intended to combine the dual merits of individual autonomy with organizational solidarity. As may be inferred from the positions of freelancers and their workplace SOHOs or organization members and their corporate officers in the two figures, individual autonomy and organizational solidarity have until now been viewed as forming a trade-off relationship ${ }^{40}$. However, through presenting an alternative scenario whereby autonomous entities (jointly) work in a place that is open to the outside, there has been an integration of individual autonomy with organizational solidarity.

The parties (pioneering practitioners or supporters, etc.) that promote coworking tend to stress the positive aspects that are drawn from such concept ${ }^{41}$. In specific terms, these refer to the lively communication and joint works between users that are made possible by the highly innovative and flexible work style that is coworking, the creation of communities centered on such spaces, and the spillover economic effects on the local society. Moreover, for the entities that expound such arguments, coworking may be viewed as a type of social movement aimed at shifting work styles towards the top right part of the figures ${ }^{42}$.

However, it needs to be remembered that the positions displayed in the two figures are nothing more than "conceptual." In reality, it has been indirectly and directly confirmed that there are individuals and spaces that don't embody the concept of coworking; for example, isolated coworkers who hardly contact with other people, or coworking spaces akin to shared offices in that hardly any communication takes place between the occupants ${ }^{43}$. On the other

\footnotetext{
${ }^{38}$ Concerning details on trends of incubation facilities or business incubators, see, for example, Nogi (2003).

39 For example, see Botsman and Rogers (2010).

40 As was mentioned in Section 2, ways of working that balance individual autonomy with cooperation with others have been practiced among some professions such as artists, however, in the world primarily comprising white-collar workers targeted here, debate on conceptualization for unifying both aspects has been sparse.

41 For example, Jones et al. (2009) emphasize the merits of coworking while conceptually comparing the respective features of enterprises and coworking spaces in an overly simplified form.

${ }^{42}$ Of course, it is good that there are more options for work styles and work spaces; however, it is necessary to pay attention to discussions for positioning coworking as the direction that "should" be aimed for by individuals and organizations.

43 For example, the manager of "Coworking Café 36" in Sapporo indicated a similar viewpoint after observing coworking spaces in Tokyo. For details, see Coworking Café 36 http://coworkingcafe36.com/index.html.
} 
hand, there are organization members, freelancers and small-scale entrepreneurs, etc. who do not utilize coworking spaces but nevertheless build close contacts with a diverse range of other people and link such contacts to joint activities ${ }^{44}$.

To begin with, among freelancers and small-scale entrepreneurs who are the primary practitioners of coworking, there are many who wish to avoid excessive mutual intervention, interference and constraints of human relations ${ }^{45}$. Moreover, there is a harsh side to working in coworking spaces in that, because there is no "obligation" to take part in communication and joint activities, it is possible for other people who share the workplace to easily change relationships according to their personality and capability. Accordingly, it is possible to imagine situations where individuals lacking in skills and experiences are unable to truly realize their anticipated way of working and end up experiencing greater dissatisfaction and disappointment than they would otherwise.

Of course, this paper has no intention whatsoever of emphasizing the negative aspects of coworking. Rather, it aims to show that newly emerging or attention-grabbing phenomena often tend to become the subjects of arguments that stress either the positive or negative aspects. In the arguments about Coworking, being no exception to this, there is currently a tendency that highlights its positive aspects.

For this reason above all, it is necessary to closely observe the phenomenon of coworking with a view to elucidating in detail its actual conditions and mechanisms without descending into simplistic optimism or pessimism.

\section{Conclusion}

This paper has tried to shed some light on "coworking," which despite attracting increasing attention in Japan and other countries in recent years has undergone hardly any theoretical examination.

As a result, it has been shown, albeit provisionally, that coworking can be more specifically and systematically grasped based on the two concepts of coworker, i.e. working individual, and coworking space, i.e. workplace. Also, through conducting comparative examination of the associated concepts of these basic ones, the dimensions for relativizing the two concepts and their theoretical status have been demonstrated (see Figures 1 and 2). Moreover, in view of the above examinations, the status of coworking on the "work style" level has been established and

\footnotetext{
${ }^{44}$ In view of this, the objectives of coworking largely include the aspects of support for human resources and business development via communications (from the individual viewpoint, growth and development). Therefore, it may be beneficial to invoke knowledge from such fields as entrepreneurial support and organizational learning.

${ }^{45}$ For example, see Uda (2005).
} 
important points for theoretically examining coworking in the future have been discussed.

The provisionally demonstrated theoretical status of coworker, i.e. working individuals, and coworking space, i.e. workplace, are deemed to possess a certain degree of theoretical and practical implications. Having said that, so far no similar studies have been made ${ }^{46}$ and the dimensions presented earlier can be applied not only to coworkers or coworking spaces but also a variety of individuals and workplaces.

However, in order to realize further theoretical and practical applications, the following kinds of initiatives are required. First, it is necessary to closely review and construct an elaborate theoretical framework for the fields that relate to the concepts of working individuals and workplaces discussed in this paper ${ }^{47}$. Certainly there has so far been scant research that directly deals with the phenomenon of coworking, however, this does not mean that useful academic knowledge for discussing coworking does not exist. Actually, there is an abundance of previous research that deals with working individuals and workplaces. Just looking at the arguments that are deeply linked to "Management Studies or Business Administration", entrepreneurship theory and career theory address the attitudes and behavior of freelancers and small-scale entrepreneurs who account for the large majority of coworkers, while office design and workspace theory address coworking spaces.

Next, it is necessary to grasp the actual conditions and mechanisms of coworking in Japan and other countries while developing the above theoretical examinations and the like. When doing this, it is necessary to turn attention to the context that surrounds coworkers and coworking spaces. For example, in Japan's case, the business environment in provincial areas is harsher than that in Tokyo. No matter how well spaces are prepared, if the context differs, disparities will naturally arise in terms of the goals of individuals in using spaces and the results they achieve from them. Also, for example, it is pointed out that differences will naturally arise in terms of space design and operation between Japan and the United States, where casual communication with others is more culturally established ${ }^{48}$. In that sense, the efforts of Mebic Ogimachi $^{49}$, which is not so much a coworking space but rather an incubation facility that

\footnotetext{
${ }^{46}$ For example, in fields such as entrepreneurship theory and career theory described later, there is no research that strives to theoretically examine interrelationship of concepts related to working individual including coworker. The same can also be said regarding the interrelationship of concepts related to work place including coworking space. Concerning the reasons why, upon checking discussions about work space in recent years, there has seemed to be a trend that stress the construction of conneciton and knowledge in the framework of "corporate offices" (Ikeda, 2011; Kishimoto, 2011). Of course, it will be necessary to painstakingly amass associated knowledge through conducting detailed review related to this concept.

${ }^{47}$ In addition, for example, in order to subsume the characteristics of "jobs" performed by working individuals and the (cooperative) relationships between working individuals as well as working individuals and supporters, it may be effective to conduct review of related fields.

${ }^{48}$ For example, see Satani (2012).

49 Established in May 2003 by Osaka City Economic Bureau and operated by Osaka Urban Industry Promotion Center, this facility initiates entrepreneurial support programs in creative fields. When it first opened, similar to conventional incubation facilities, it devoted its efforts to executing programs "within" the facility, however, as a result of reflection by the facilities managers, it has steadily shifted its approach to examining the operation of
} 
conducts pioneering development and support programs for entrepreneurial activities in the context of the local area, contain significant implications.

Accordingly, it will be important to investigate and preferentially approach actors that are striving to redefine and rearrange ways of working (including the practices of working individuals) and workplaces utilizing the concept of coworking without being fettered by that label.

\section{References}

Botsman, R. and R. Rogers (2010) What's Mine is Yours: The Rise of Collaborative Consumption, New York: HarperCollins.

DeGuzman, G. V. and A. I. Tang (2011) Working in the "UnOffice": A Guide to Coworking for Indie Workers, Small Businesses, and Nonprofits, San Francisco: Night Owls Press.

Fraser, J. and M. Gold (2001) “'Portfolio Workers': Autonomy and Control amongst Freelance Translators," Work, Employment and Society, Vol. 15, No. 4, pp. 679-697.

Hijikata, M., H. Shinmyo and K. Ejiri (2004) The Prime of Hideo Oguma and the Artists: Ikebukuro Montparnasse, Nerima Art Museum

Ikeda, K. (2011) Copresence Work, Nikkei Business Publications, Inc.

Jones, D., T. Sundsted and T. Bacigalupo (2009) I'm Outta Here: How Coworking is Making the Office Obsolete, Austin: Not an MBA Press.

Kishimoto, A. (2011) New Workscape: Office Designs to Change Work, Koubundou Publishers Inc.

Lave, J. and E. Wenger (1991) Situated Learning: Legitimate Peripheral Participation, Cambridge: Cambridge University Press.

Moralee, L. (1998) "Self-Employment in the 1990s," Labour Market Trends, Vol. 106, No. 3, pp. 121-130.

Nogi, D. (2003) "The Construction Process of the Business Incubator Concept", Ventures Review, Vol. 4, pp. 113-120.

Okada, T. (2004) "Voyage a La Ruche", Bulletin of the College of Community ands Human Services, Rikkyo University, Vol. 6, pp.111-118.

Ratcliff, C. (1983) Andy Warhol, New York: Abbeville Press (translated by Akiko Hyuga and Sachi Kogabayashi, Bijutsu Shuppan-sha Co., LTD.)

facilities within the context of local industry and area. In concrete terms, from 2007 it commenced a program geared to transforming Mebic Ogimachi from a simple incubation facility into a place for physically connecting creators active both inside and outside of the facilities. For detailed account of these initiatives, for example, see Uda and Takahashi (2006). For current activities, see the Mebic Ogimachi homepage at http://www.mebic.com/about/. 
Satani, K., K. Nakaya and Y. Fujiki (2012) Tsunagari no Shigoto-jutsu, Yosensha Publishing Co. Ltd.

Shibata, M. (1999) Montparnasse, La Formation d'une Quartier avec des Artistes Community, Treatises and Studies by the Faculty of Kinjo Gakuin University, Vol. 32, pp. 157-172.

Spinuzzi, C. (2012) "Working Alone Together: Coworking as Emergent Collaborative Activity," Journal of Business and Technical Communication, Vol. 26, No. 4, pp. 399-441.

Steinmetz, G. and E. O. Wright (1989) "The Fall and Rise of the Petty Bourgeoisie: Changing Patterns of Self-Employment in the Postwar United States," American Journal of Sociology, Vol. 94, No. 5, pp. 973-1018.

Uda, T. (2005) “A New Perspective of Entrepreneurial Career”, Ventures Review Vol. 6, pp. $35-44$.

Uda, T. (2007) “A Review of Boundaryless Career Concept,” Economic Studies, Vol. 57, No. 1, pp. 63-84.

Uda, T. (2009) "Heroes, Knights, and Pages: A Review of Discourse on Freelance", Economic Studies, Vol. 59, No.3, pp. 215-224.

Uda, T. and M. Takahashi (2006) "An Analytical Framework for Incubator Activity: Interaction between Managers and Entrepreneurs in Mebic Ogimachi," Entrepreneurial Studies, No. 3, pp. 28-44. 